\section{Predictive approach to optimize the number of visual graders for indirect selection of high- yielding Urochloa ruziziensis genotypes}

\author{
Jales Mendes Oliveira Fonseca ${ }^{1}$, José Airton Rodrigues \\ Nunes ${ }^{2 *}$, Flavia Maria Avelar Gonçalves ${ }^{2}$, Fausto de Souza \\ Sobrinho ${ }^{3}$, Flávio Rodrigo Gandolfi Benites ${ }^{3}$ and Davi Henrique \\ LimaTeixeira ${ }^{4}$
}

\begin{abstract}
Forage plant breeders often use visual scores to assess agronomic traits because of the costs associated with in-depth phenotyping in the initial stages of breeding cycles. The aim of this study was to investigate the impact of the number of graders on the effectiveness of indirect selection of high-yielding genotypes and determine an optimal number of graders in the early-stage trials of Urochloa ruziziensis. For that purpose, five graders assessed 2.219 U. ruziziensis genotypes in an augmented block design. Biomass production and vigor scores were evaluated in two cuts and were analyzed using a linear mixed model approach. Vigor scores were analyzed considering each grader's score and the combinations of two, three, four, and five graders. Genetic variance was significant for both traits. Visual evaluation was effective in identifying productive genotypes based on the statistical criteria. The optimal number of graders for indirect selection of high-yielding U. ruziziensis genotypes is three.
\end{abstract}

Keywords: Brachiaria ruziziensis, visual selection, accuracy, forage breeding.

\section{INTRODUCTION}

Urochloa ruziziensis (R. Germ. and CM Evrard) Crins. (synonym Brachiaria ruziziensis) is a forage species with high agronomic and nutritional potential widely used in breeding programs (Marcelino et al. 2020). Some agronomic traits in U. ruziziensis and other forages are often visually assessed under field conditions because this assessment is practical and effective. Traits routinely evaluated using such techniques include i) pest and disease resistance (Silva et al. 2013), ii) regrowth capacity (Berchembrock et al. 2020, Gouveia et al. 2020), iii) stay-green (Wilkinson and Hill 2003), and iv) plant growth and biomass production (Burton 1982, Price and Casler 2014).

Several factors might affect the effectiveness of visual selection in forage breeding, such as genetic control of the trait and the number of graders or evaluators. For quantitative traits, such as grain yield, some studies have reported low effectiveness (Abreu et al. 2010, Abadassi 2014). However, visual selection has achieved satisfactory results in $U$. ruziziensis for quantitative traits, such as pest resistance (Souza Sobrinho et al. 2010) and vigor (Teixeira
Crop Breeding and Applied Biotechnology 20(3): e329220314, 2020 Brazilian Society of Plant Breeding. Printed in Brazil http://dx.doi.org/10.1590/198470332020v20n3a48

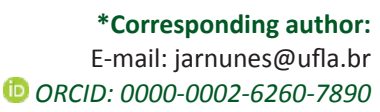

Received: 15 April 2020 Accepted: 02 July 2020 Published: 28 August 2020

${ }^{1}$ Texas A\&M University, College Station, 77843, Texas, United States 2 Universidade Federal de Lavras, Departamento de Biologia, 37.200-900, Lavras, MG,

Brazil

${ }^{3}$ Embrapa Gado de Leite, 36155-000, Coronel Pacheco, MG, Brazil

${ }^{4}$ Universidade Federal Rural da Amazonia, Travessa Pau Amarelo, Vila Nova, 68.650-000, Capitão Poço, PA, Brazil 
et al. 2020). The number of graders was examined by Abreu et al. (2010), who investigated strategies to improve mass selection in maize using ten graders. Helms et al. (1995) indirectly selected high-yielding soybean lines using three graders. Bowman et al. (2004) also used three graders to select for yield in cotton. However, none of these studies explained why the respective numbers of graders were adopted. Similarly, in $U$. ruziziensis, some studies used visual evaluation to derive phenotypic measurements (Teixeira et al. 2020), but the importance or effect of the number of graders on the results presented was not discussed.

The applicability of visual evaluation goes beyond the scope of forage breeding. Animal breeders commonly assess relevant traits using visual scores. For instance, the percentage of muscle and fat, marketable cuts, and carcass traits are assessed via visual scores (Conroy et al. 2010). However, as with plants, an explanation that justifies the use of a certain number of graders is lacking. Toral et al. (2011) estimated the response to selection for post-weaning daily weight gains involving 47.000 animals using visual scores on related traits (i.e., conformation, precocity and muscling). In that case, groups of animals were established and a single grader ranked each group; however, no reasons were given in regards to the adoption of a single-grader approach.

Determining an optimal number of graders could provide better estimates of genetic parameters and more accurate breeding values. Equally important, this optimal number is likely to improve the effectiveness of the breeding pipeline and, ultimately, the rates of genetic gain. However, before determining this number, the correlation of selection with the trait of interest and the quality of the experimental data set must be assessed (Price and Casler 2014). Once these estimates are available and proven to be useful, a predictive approach for optimizing the number of graders should be performed. Therefore, the objectives of this study were to i) investigate whether the number of graders affects the effectiveness of indirect selection of high-yielding $U$. ruziziensis genotypes and ii) determine an optimal number of graders to assess $U$. ruziziensis genotypes within a forage breeding program.

\section{MATERIAL AND METHODS}

The experiment was conducted at the Embrapa Gado de Leite (Embrapa Dairy Cattle) experimental station (lat $21^{\circ} 33^{\prime}$ $\mathrm{S}$, long $43^{\circ} 06^{\prime} \mathrm{W}$, alt $410 \mathrm{~m}$ asl) in Coronel Pacheco, MG, Brazil. The soil type at this site was predominantly an Argissolo Vermelho-Amarelo Alumínico (Santos et al. 2006). The climate is classified as humid subtropical (Cwa type mesothermic) according to Köppen, characterized by low rainfall during the winter season and an annual mean temperature of $19^{\circ} \mathrm{C}$. The region typically has dry and cold winters, whereas the summer season is predominantly humid with moderate to high temperatures. Mean annual rainfall is $1.536 \mathrm{~mm}$.

An experiment in an augmented block design, consisting of 51 blocks ranging from 28 to 72 genotypes within each block, was carried out in August 2011. Regular treatments consisted of 2.219 U. ruziziensis genotypes derived from selected seeds in the second recurrent intraspecific cycle of the Embrapa Dairy Cattle breeding program. Two check cultivars, Marandu (U. brizantha) and Basilisk ( $U$. decumbens), were replicated treatments. Plots consisted of a single plant with an average area of $1.5 \mathrm{~m}^{2}$, which were spaced one meter apart from each other.

At planting, $350 \mathrm{~kg} \mathrm{ha}^{-1}$ of the formulation 8-28-16 (nitrogen-phosphorus-potassium) was applied. For topdressing fertilization, 1 ton ha-1 of the formulation 20-05-20 (nitrogen-phosphorus-potassium) was fractionated over the cuts. Manual weeding was performed when necessary, and a cut to homogenize the trial was carried out at the beginning of December 2011. In 2012, two evaluation cuts were performed, one in January and another after around 40 days.

Biomass production (grams) and vigor scores associated with plant yield were measured as follows. Visual scores ranged from 1 to 5 as described in the following scale: 1 - very bad, 2 - bad, 3 - average, 4 - good, and 5 - very good. Five graders, including forage breeders, graduate students, and technicians, performed visual phenotyping right before each cut. All five graders assessed all genotypes in both cuts. To evaluate biomass production, plants were cut at 5.0 $\mathrm{cm}$ above soil level; then, the biomass harvested was weighed using a portable suspension scale.

Phenotypic data were analyzed using a mixed model approach (Henderson 1984) with recovery of interblock and intergenotypic information. Biomass production data were fitted according to statistical model 1, while model 2 was used for vigor score data. 


$$
\begin{gathered}
y=X \mu+Z_{1} b .+Z_{2} g+e \\
y=X \mu+Z_{1} b .+Z_{2} s+Z_{3} g+e
\end{gathered}
$$

where $y$ is the vector of biomass production or vigor score data; $\mu$ is the intercept; $X, Z_{1}, Z_{2}$, and $Z_{3}$ are incidence matrices of model effects; $b$ is the vector of block effects, $b \sim N\left(0, l \sigma_{b}^{2}\right) ; g$ is the vector of genotype effects, $g \sim N\left(0, I \sigma_{g}^{2}\right) ; s$ is the vector of grader effects, $s \sim N\left(0, l \sigma_{s}^{2}\right)$; and $e$ is the vector of errors, $e \sim N\left(0, l \sigma_{\mathrm{e}}^{2}\right)$. Specifically for model $2, y$ corresponded to the vigor score attributed by each grader in the case of two or more graders.

For both traits, the estimation of fixed effects (best linear unbiased estimator - BLUE) and prediction of random effects (best linear unbiased prediction - BLUP) was performed via the solution of the Henderson equations system (Henderson 1984). Variance components were estimated by the restricted maximum likelihood (REML) method (Patterson and Thompson 1971). The Imer function of the Ime4 R package was used to fit the mixed model (Bates et al. 2015). The significance of variance components was evaluated by the likelihood ratio test considering a significance level of $5 \%$ using the ranova function of the ImerTest R package (Kuznetsova et al. 2017).

Accuracy on a genotype basis was estimated using the following estimator (Henderson 1984): $\hat{r}_{\hat{g} g}=\left(1-\frac{\overline{P E V}}{\hat{\sigma}_{q}^{2}}\right)^{1 / 2}$, where $\overline{P E V}$ is the average of prediction error variance associated with the BLUPs of the genotypes. Accuracy was interpreted as a measure associated with precision in selection according to Resende and Duarte (2007). In addition, the coefficient of experimental variation (CV) was estimated for both traits.

The effectiveness of indirect selection for biomass production based on visual selection for vigor scores was assessed by estimation of the following criteria regarding the variable number of graders: the Spearman correlation between the BLUPs of genotypes for vigor score and biomass production, and relative genetic gain for biomass production regarding the top $5 \%$ of selected genotypes based on the vigor score.

The relative genetic gain (\%) was estimated according to the estimator $R G=\left(\overline{B L U P}_{y / y^{\prime}} \overline{B L U P_{y}}\right) / \times 100$, where $\overline{B L U P_{y / y}}$ is the indirect genetic gain for biomass production computed by the average of BLUPS for biomass production $(y)$ of the top $5 \%$ of selected genotypes ranked as based on BLUPs for vigor score ( $\left.y^{\prime}\right)$ regarding different numbers of visual graders, and $B L U P_{y}$ is the direct genetic gain for computed by the average of BLUPs for biomass production $(y)$ of the top $5 \%$ of high-yielding genotypes.

Parameter estimates were visualized graphically using boxplots created in the stat R package (R Core Team 2019).

\section{RESULTS}

Genetic variance for biomass production and vigor score was significant at a nominal significance level of 5\% (Table 1). The variance component associated with the grader effect was also significant regarding the average of the vigor score from five graders (Table 1). The accuracy on a genotype basis was 0.64 for biomass production, while for vigor scores, the values ranged from 0.56 to 0.74 among graders. For the average score from five graders, the accuracy was higher (0.96). The accuracies observed indicate high selection reliability for both traits. Lower CV estimates for vigor scores (13-21\%) compared to those for biomass production (30\%) were also observed (Table 1 ).

Table 1. Genetic variance $\left(\sigma_{g}^{2}\right)$, grader variance $\left(\sigma_{s}^{2}\right)$, residual variance $\left(\sigma_{e}^{2}\right)$, accuracy on a genotype basis $\left(r_{\hat{g} g}\right)$, and experimental

\begin{tabular}{|c|c|c|c|c|c|c|c|}
\hline \multirow{2}{*}{ Parameters } & \multirow{2}{*}{$\begin{array}{c}\text { Biomass } \\
\text { production }\end{array}$} & \multicolumn{6}{|c|}{ Vigor Score } \\
\hline & & A & B & $\mathrm{C}$ & D & $\mathbf{E}$ & $\overline{\text { A..E }}$ \\
\hline$\sigma_{g}^{2}$ & $74511^{*}$ & $0.25^{*}$ & $0.19 *$ & $0.21^{*}$ & $0.17^{*}$ & $0.27^{*}$ & $0.48^{*}$ \\
\hline$\sigma_{s}^{2}$ & - & - & - & - & - & - & $0.06^{*}$ \\
\hline$\sigma_{e}^{2}$ & 102034 & 0.40 & 0.36 & 0.44 & 0.35 & 0.21 & 0.15 \\
\hline$r_{\hat{g} g}$ & 0.64 & 0.61 & 0.59 & 0.56 & 0.57 & 0.74 & 0.96 \\
\hline $\mathrm{CV}$ & 0.30 & 0.21 & 0.18 & 0.21 & 0.20 & 0.17 & 0.13 \\
\hline
\end{tabular}
coefficient of variation (CV) for biomass production (grams), and vigor score for each grader (A-E) and average of five graders (A..E)

* Significant by the likelihood ratio test at $5 \%$. 
Estimates of genetic variance (Figure 1), accuracy (Figure 2), and CV (Figure 3) varied according to the number of graders. The variation was substantial when fewer graders were used. The average of the estimates stabilized after three or more graders. Similar results were found for the correlations between the BLUPs for biomass and vigor scores (Figure 4). Correlation averages across the grader combinations ranged from $77 \%$ to $86 \%$ when one and five graders, respectively, were considered.

Comparisons among indirect selections based upon the different number of graders showed significant differences (Figure 5). The expected direct gain for biomass production was $37 \%$ when the top $5 \%$ of high-yielding genotypes was selected. The relative genetic gain for biomass production due to indirect selection of the top $5 \%$ of selected genotypes based on the visual scores was expressive $(68-77 \%)$ and higher when the number of graders increased (Figure 5).

\section{DISCUSSION}

The effectiveness of the vigor score for selection was investigated under various numbers of graders by estimating the correlation between the biomass and vigor scores of genotypic BLUPs and relative genetic gain. Results from this experiment showed a significant increase in these parameters when increasing the number of graders. Indirect genetic selection for biomass production based on vigor scores from three or more graders was able to recovery at least $74 \%$ of the direct gain. This result indicates that scores might be feasible to indirectly select high-yielding genotypes (Figures 4 and 5). Analyzing the boxplots where a single grader is scoring all genotypes shows that most of the genotypes are misclassified at a $5 \%$ selection intensity. Hence, decisions based on a single grader could impair the progress of a forage breeding program.

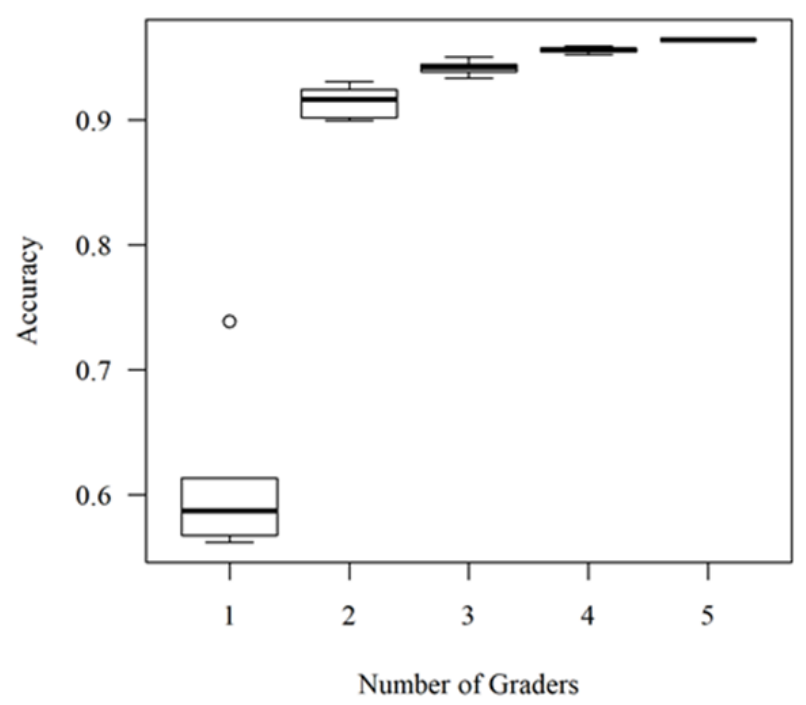

Figure 2. Boxplot of accuracy estimates on a genotype basis for vigor score considering different numbers of visual graders.

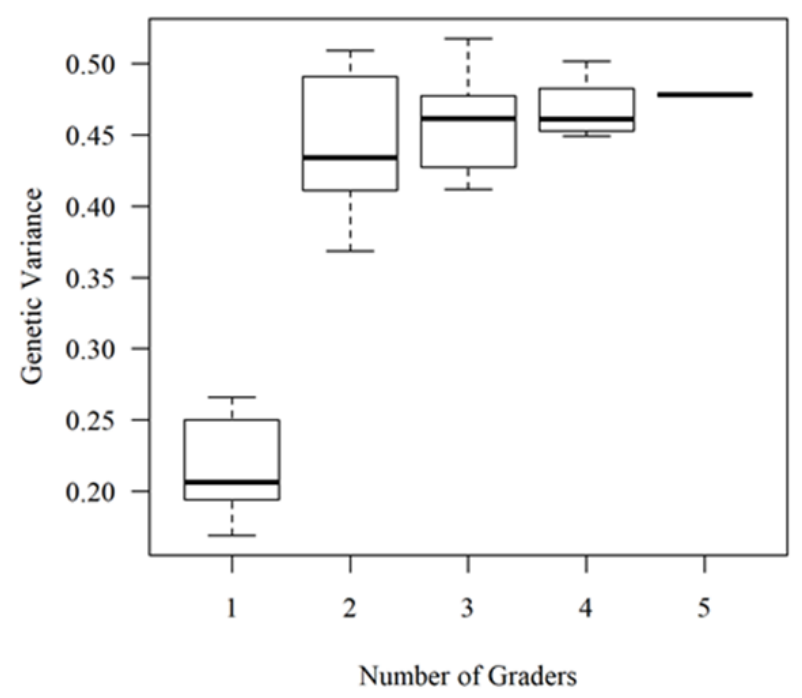

Figure 1. Boxplot of the estimates of genetic variance for vigor score considering different numbers of visual graders.

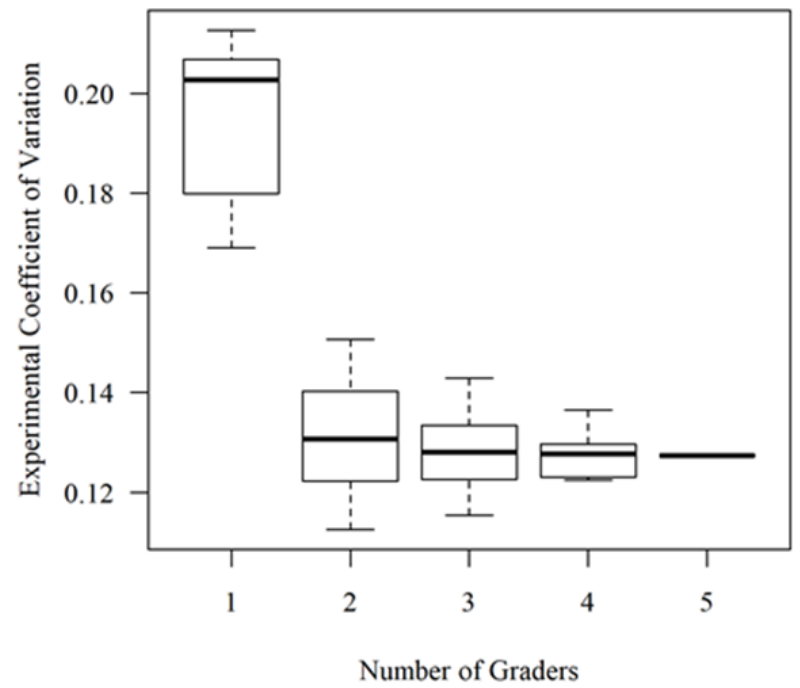

Figure 3. Boxplot of the estimates of the experimental coefficient of variation for vigor score considering different numbers of visual graders. 
When three or more graders assessed all genotypes, the number of true-positive genotypes (i.e., plants that look good and have better yield) increased, while the falsenegative rate remained stable. However, indirect selection can also be used to eliminate poor and non-adapted genotypes. In this case, even though some promising genotypes could be eliminated (type II error), most of the genotypes expressing unsatisfactory performance are correctly classified. Hence, forage breeding programs could benefit from allocating resources to fewer genotypes in the following generations. Nevertheless, in both cases (selecting versus discarding), it is important to consider that perennial grass breeding programs have a peculiar regrowth evaluation (Berchembrock et al. 2020), which limits the number of generations and selection cycles on a per year basis. Various forage breeding programs have used visual evaluation to assess traits at different stages of selection cycles for crops such as red clover (Riday 2009), $U$. ruziziensis (Souza Sobrinho et al. 2010, Teixeira et al. 2020), U. decumbens (Matias et al. 2020), U. humidicola (Figueiredo et al. 2019), and Urochloa spp. (Gouveia et al. 2020). Teixeira et al. (2020) showed the effectiveness of visual selection for green biomass yield based on plant vigor in U. ruziziensis. Souza Sobrinho et al. (2010) also highlighted the efficiency of visual evaluation in $U$. ruziziensis by indirectly selecting genotypes resistant to spittlebugs. That study described the evaluation of $U$. ruziziensis genotypes in the early stage of a selection cycle at the Embrapa breeding program. That stage is characterized by a large number of genotypes expressing high variability in biomass production, revealing that the use of scores is effective through its practicality in phenotyping and savings in resources. Moreover, the visual vigor score has high heritability, achieving values greater than 0.88 when three or more graders are used, which enables its use in a $U$. ruziziensis breeding program.

Another aspect related to the evaluation of genotypes in the early stage of a selection cycle is the use of the augmented block design (ABD). This design is recommended at such stages due to its flexibility and especially since it allows testing of non-replicated genotypes. However, its estimates of variance components are generally less accurate than estimates from other designs, such as the randomized complete block design - RCBD (Santos et al. 2002). Figueiredo et al. (2012) found higher accuracy values when analyzing the regrowth score in Urochloa humidicola in a RCBD. The fact that estimates from the ABD are less accurate might partially explain the low magnitudes of genetic variance estimates for biomass production and vigor scores (Table 1). Even so, it is noteworthy that at this early stage, the differences to be detected are higher, so the use of $A B D$ is feasible. Moreover, the ABD allows evaluation of more genotypes and application of high selection intensity, which result in higher genetic gain (Silva Filho 2013).

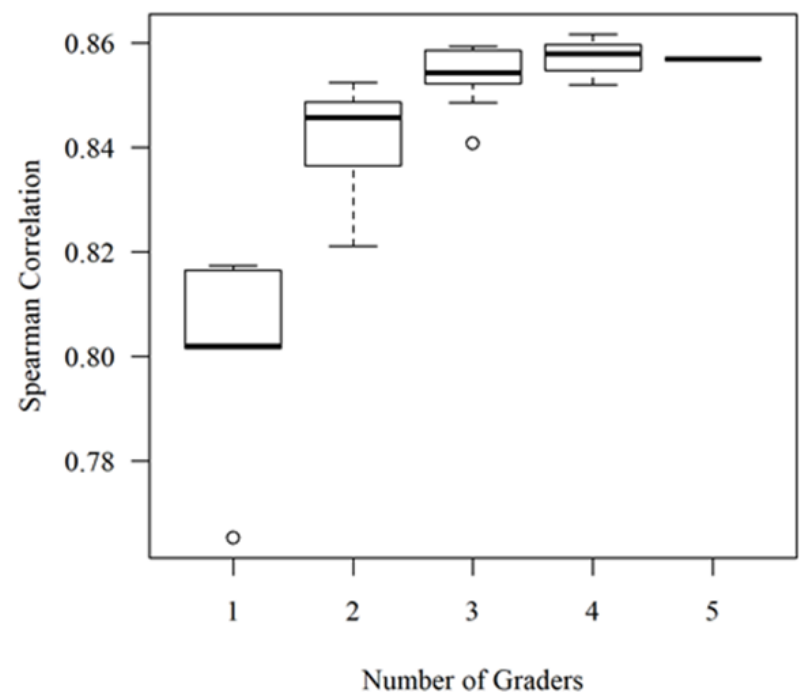

Figure 4. Boxplot of Spearman correlations between BLUPs of genotypes for biomass production and vigor score considering different numbers of visual graders.

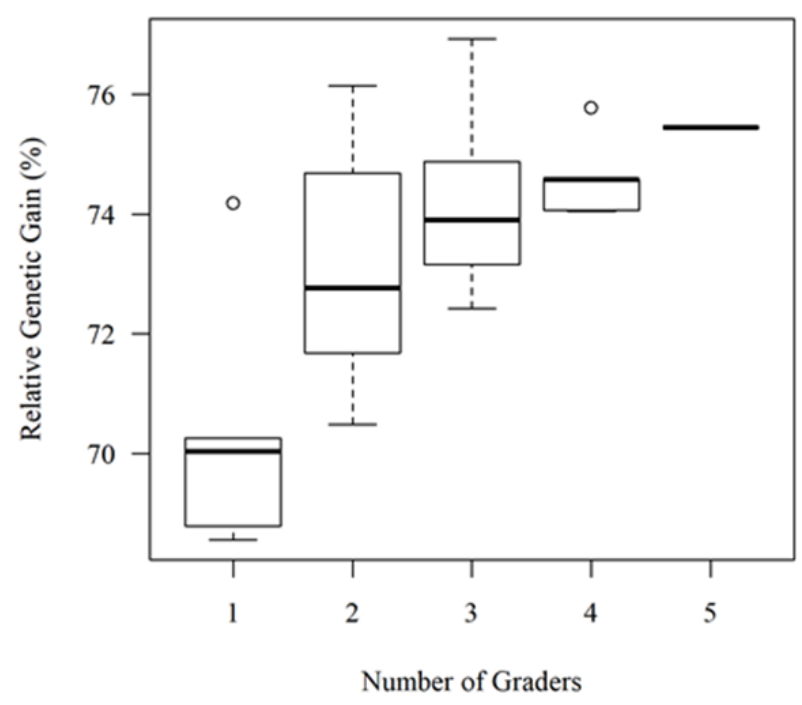

Figure 5. Boxplot of relative genetic gain (\%) for biomass production based on the top $5 \%$ of selected genotypes for vigor score considering different numbers of visual graders. 
Several factors might affect the effectiveness of visual evaluation. Results of this study showed that the number of graders affects genetic variance, accuracy, and CV estimates, especially when a single grader is considered. In addition, the use of three or more graders to score genotypes proved to be more reliable. Furthermore, it should be highlighted that the experience of the grader, the difficulty of scoring some traits, and the time consumption associated with visual resting might also affect the effectiveness of visual selection. The breeder should also consider new tools for indirect selection of high-yielding $U$. ruziziensis genotypes, such as the use of high-throughput phenotyping (HTP) based on remote sensing (Yang et al 2017, Maes and Steppe 2019). However, the practical use of HTP in experiments of U. ruziziensis requires more studies to validate its protocol in the routine practices of the forage breeding program.

Finally, our results suggested that the optimal number of graders might be three because there are no substantial changes in estimates beyond that number, dispensing with the inclusion of more graders. However, it should be noted that these results are limited to the current study. More studies considering $U$. ruziziensis under different conditions are needed, such as more cuts, different seasons (rainy or dry seasons), and different sowing dates. The concept of an optimal number of graders then becomes more precise.

\section{CONCLUSION}

The number of graders affects the effectiveness of visual evaluation for biomass production in $U$. ruziziensis. For optimization purposes, the use of three graders is recommended.

\section{ACKNOWLEDGMENTS}

The authors are grateful to Embrapa Gado de Leite for supporting this study, to the Coordenação de Aperfeiçoamento de Pessoal de Nível Superior - Brasil (CAPES) for partial funding of this study - Finance Code 001, and to the Conselho Nacional de Desenvolvimento Científico e Tecnológico - Brasil (CNPq) and the Fundação de Amparo à Pesquisa de Minas Gerais (FAPEMIG) for supporting the Graduate Studies Program in Genetics and Plant Breeding at the Universidade Federal de Lavras. We also wish to thank Dr. Geraldo Carvalho Jr. for comments on the manuscript.

\section{REFERENCES}

Abadassi J (2014) Mass selection to improve grain yield in a traditional tropical maize population. International Journal of Science and Technology 4: 371-392.

Abreu GB, Ramalho MAP, Toledo FHRB and Souza JC (2010) Strategies to improve mass selection in maize. Maydica 55: 219-225.

Bates D, Mächler M, Bolker BM and Walker SC (2015) Fitting linear mixed-effects models using \{lme4\}. Journal of Statistical Software 67: 1-48.

Berchembrock YV, Figueiredo UJ, Nunes JAR, Valle CB and Barrios SCL (2020) Comparison of selection methods among and within full-sibling progenies in Urochloa humidicola. Grass Forage Science 00: 1-8.

Bowman DT, Bourland FM, Myers GO, Wallace TP and Caldwell D (2004) Visual selection for yield in cotton breeding programs. Journal of Cotton Science 8: 62-68.

Burton GW (1982) Improved recurrent restricted phenotypic selection increases bahiagrass forage yields. Crop Science 22: 1058-1061.

Conroy SB, Drennan MJ, Kenny DA and McGee M (2010)
The relationship of various muscular and skeletal scores and ultrasound measurements in the live animal, and carcass classification scores with carcass composition and value of bulls. Livestock Science 127: 11-21.

Figueiredo UJ, Barrios SC, Valle CB and Nunes JAR (2019) Combining ability among apomictic and sexual parents of Urochloa humidicola. Grass and Forage Science 74: 678-686.

Figueiredo UJ, Nunes JAR and Valle CB (2012) Estimation of genetic parameters and selection of Brachiaria humidicola progenies using a selection index. Crop Breeding and Applied Biotechnology 12: 237-244.

Gouveia BT, Barrios SCL, Valle CB, Gomes RC, Machado WKR, Bueno Filho JSS and Nunes JAR (2020) Selection strategies for increasing the yield of high nutritional value leaf mass in Urochloa hybrids. Euphytica 216: 1-12.

Henderson CR (1984) Applications of linear models in animal breeding. University of Guelph, Guelph, 384p.

Helms TC, Orf JH and Scott RA (1995) Actual yield advance from selection for visual score and yield. Canadian Journal of Plant Science 75: 187-189.

Kuznetsova A, Brockhoff PB and Christensen RHB (2017) 
ImerTest package: Tests in linear mixed effects models. Journal of Statistical Software 82: 1-26.

Maes WH and Steppe K (2019) Perspectives for remote sensing with unmanned aerial vehicles in precision agriculture. Trends in plant science 24: 152-164.

Marcelino LL, Moreira GR, Souza Sobrinho F, Almeida MIV, Cóser AC, Cunha GM and Benites FRG (2020) Nutritive value of improved populations Brachiaria ruziziensis. Semina: Ciências Agrárias 41: 323-334.

Matias FI, Valle CB, Gouveia BT, Moro GV and Barrios SCL (2020) Using additive indices and principal components to select sexual genitors and hybrids of Urochloa decumbens. Crop Breeding and Applied Biotechnology 20: e28082022.

Patterson HD and Thompson R (1971) Recovery of inter-block information when block sizes are unequal. Biometrika 58: 545-554.

Price DL and Casler MD (2014) Divergent selection for secondary traits in upland tetraploid switchgrass and effects on sward biomass yield. BioEnergy Research 7: 329-337.

R Core Team (2019). R: A language and environment for statistical computing. R Foundation for Statistical Computing, Vienna.

Resende MDV and Duarte JB (2007) Precisão e controle de qualidade em experimentos de avaliação de cultivares. Pesquisa Agropecuária Tropical 37: 182-194.

Riday H (2009) Correlations between visual biomass scores and forage yield in space planted red clover (Trifolium pratense L.) breeding nurseries. Euphytica 170: 339-345.

Santos AH, Bearzoti E, Ferreira DF and Silva Filho JLD (2002) Simulation of mixed models in augmented block design. Scientia Agricola 59: 483-489.

Santos HG, Jacomine PKT, Anjos LHC, Oliveira VA,
Oliveira JB, Coelho MR, Lumbreras JF and Cunha TJF (2006) Sistema brasileiro de classificação de solos. Embrapa, Rio de Janeiro, 306p.

Silva DM, Moraes JC, Auad AM, Fonseca MG and Souza Sobrinho F (2013) Genetic variability of Brachiaria ruziziensis clones to Collaria oleosa (Hemiptera: Miridae) based on leaf injuries. American Journal of Plant Sciences 4: 2418-2424.

Silva Filho JL (2013) Optimizing the number of progenies and replications in plant breeding experiments. Crop Breeding and Applied Biotechnology 13: 151-157.

Souza Sobrinho F, Auad AM and Lédo FJS (2010) Genetic variability in Brachiaria ruziziensis for resistance to spittlebugs. Crop Breeding and Applied Biotechnology 10: 83-88.

Teixeira DHL, Gonçalves FMA, Nunes JAR, Souza Sobrinho F, Benites FRG and Dias KOG (2020) Visual selection of Urochloa ruziziensis genotypes for green biomass yield. Acta Scientiarum. Agronomy 42: e42444.

Toral FLB, Roso VM, Araújo CV and Reis Filho JC (2011) Genetic parameters and response to selection for postweaning weight gain, visual scores and carcass traits in Hereford and Hereford $\times$ Nellore cattle. Livestock Science 137: 231-237.

Wilkinson JM and Hill J (2003) Effect on yield and dry-matter distribution of the stay-green characteristic in cultivars of forage maize grown in England. Grass and Forage Science 58: 258-264.

Yang G, Liu J, Zhao C, Li Z, Huang Y, Yu H, Xu B, Yang X, Zhu D, Zhang $X$, Zhang R, Feng $H$, Zhao X, Li Z, Li H and Yang $H$ (2017) Unmanned aerial vehicle remote sensing for fieldbased crop phenotyping: Current status and perspectives. Frontiers in Plant Science 8: 1111. 